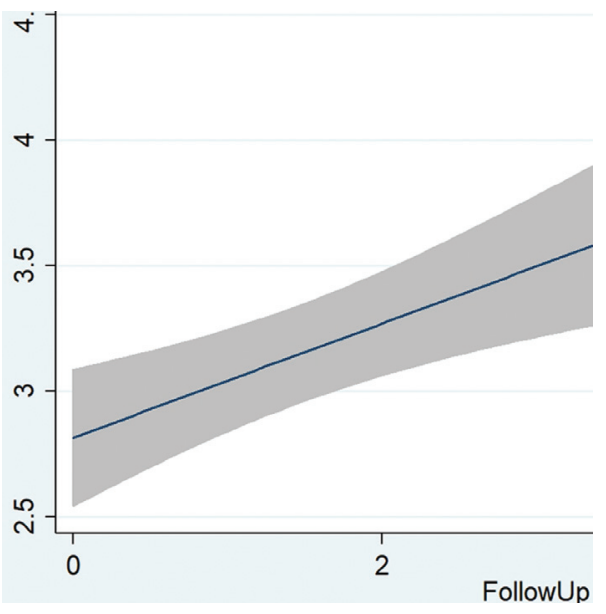

Conclusions: Work impairment is highly prevalent in contemporary rheumatoid arthritis patients. It is significantly correlated with mental health, even after adjusting for disease severity factors. Baseline mental health also predicts progression of work impairment. The relationship is likely bidirectional, and future research is justified to evaluate whether mental health interventions could improve work outcomes.

Disclosure of Interest: None declared DOI: 10.1136/annrheumdis-2018-eular.5395

\section{THU0101 TISSUE METABOLITE OF TYPE I COLLAGEN, C1M, AND CRP PREDICTS STRUCTURAL PROGRESSION OF RHEUMATOID ARTHRITIS}

A.C. Bay-Jensen ${ }^{1}$, A. Platt ${ }^{2}$, M. Jenkins ${ }^{3}$, M. Weinblatt ${ }^{4}$, I. Byrjalsen ${ }^{1}$, K. Musa ${ }^{1}$, M. C. Genovese ${ }^{5}$, M.A. Karsdall ${ }^{1}{ }^{1}$ Rheumatology, Nordic Bioscience Biomarkers and Research, Herlev, Denmark; ${ }^{2}$ Precision Medicine and Genomics; ${ }^{3}$ Global Medicines Development, AstraZeneca, Cambridge, UK; ${ }^{4}$ Division of Rheumatology, Brigham and Women's Hospital, Boston, MA; ${ }^{5}$ Division of Immunology and Rheumatology, Stanford University, Palo Alto, CA, USA

Background: Biomarkers of rheumatoid arthritis (RA) disease activity typically measure inflammation or autoimmunity (e.g. CRP, rheumatoid factor (RF)). Another class of biomarkers are structural proteins of the joint. C1M and C3M, metabolites of type I and III collagen, are such biomarkers. These biomarkers have previously been documented to provide additional value as compared to standard inflammation biomarkers, for prognosis and prediction of response to treatment ${ }^{1}$.

Objectives: We investigated the relationship of high serum levels of C1M or C3M to radiographic progression, and benchmarked to CRP levels and RF status, demonstrated to be associated with structural progression ${ }^{2}$.

Methods: Placebo treated patients of the OSK123 studies (Ph3 clinical trials testing efficacy of fostamatinib) with baseline serum biomarkers C1M, C3M, CRP and RF were included $\left(n_{B L}=474\right)$. Van der Heijde mTSS was calculated at baseline and 24 week $\left(\mathrm{n}_{24}=264\right)$. Progression was defined as moderate or rapid $(\geq 0.5$ or $\geq 5 \mathrm{mTSS}$ units/y). Patients were divided into subgroups; low, high or very high C1M, C3M and CRP (above/below median and highest quartile), or RF negative, positive and high positive $(\geq 110 \mathrm{U} / \mathrm{L})^{2}$. Difference in clinical parameters were analysed by Mann-Whitney/Chi-squared tests, and multivariate predictive calculations by Classification And Regression Tree analysis including covariates (age, $\mathrm{BMI}$, gender and disease activity assessment scores).

Results: High C1M, C3M and CRP levels were significantly associated with measures of disease activity $(p<0.05)$ and patient reported scores $(p<0.05)$. $R F_{\text {pos }}$ was also associated with disease active scores $(p<0.05)$. $R F_{\text {pos }}$ and $C R P$ $(p<0.001)$, as well as $C 1 M$ and C3M $(p<0.05)$, were significantly associated with mTSS at baseline. For prognostic measures, there were 2.5 and 4-fold as many rapid progressors in the $C 1 \mathrm{M}_{\text {high }}$ and $C R P_{\text {high }}(p<0.05)$, and in the $\mathrm{C}_{1} \mathrm{M}_{\text {veryhigh }}$ and $\mathrm{CRP}_{\text {veryhigh }}$ groups $(\mathrm{p}<0.001)$ compared $\mathrm{C}_{1} \mathrm{M}_{\text {low }}$ and $\mathrm{CRP}$ low, respectively. $\mathrm{C} 1 \mathrm{M}$ and CRP performed similarly in the predictive analysis with AUCs of 0.67 and 0.69 (table 1). The best model involving $\mathrm{C} 1 \mathrm{M}$ in predicting rapid progressor included BMI, SJC and HAQ (AUC 0.85), whereas the best model for CRP included CRP, BMI, SJC and HAQ (AUC 0.85). C3M and RF did not provide prognostic value.

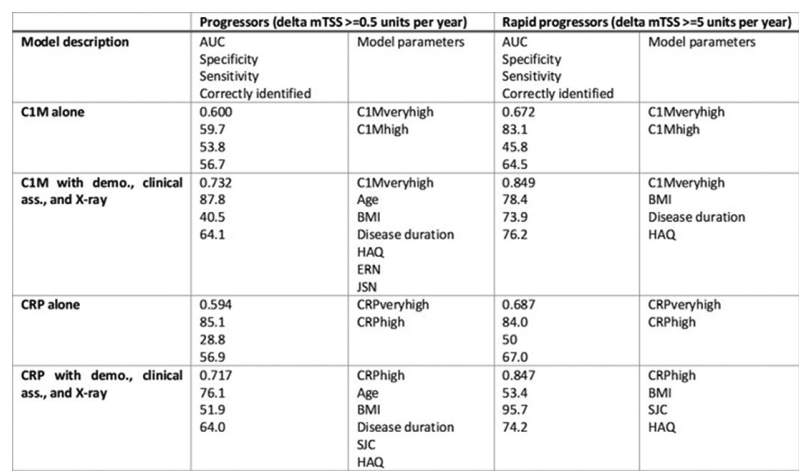

Conclusions: Of the four markers analysed only C1M and CRP were associated with structural progression. They seem to preform equally well, but reflect two different aspect of disease pathogenesis (tissue turnover vs. inflammation), thus may provide individual, but supplementary, information. These simple measures may be important for enrichment of clinical trials with structural progressors.

\section{REFERENCES:}

[1] Siebuhr A, et al. Serological identification of fast progressors of structural damage with rheumatoid arthritis. Arthritis Res. Ther 2013.

[2] Aletaha D, Alasti F, \& Smolen JS. Rheumatoid factor determines structural progression of rheumatoid arthritis dependent and independent of disease activity. Ann Rheum Dis 2013.

Disclosure of Interest: A. Bay-Jensen Shareholder of: Nordic Bioscience, Employee of: Nordic Bioscience, A. Platt Shareholder of: AstraZeneca, Employee of: AstraZeneca, M. Jenkins Employee of: AstraZeneca, M. Weinblatt: None declared, I. Byrjalsen Employee of: Nordic Bioscience, K. Musa Employee of: Nordic Bioscience, M. Genovese: None declared, M. Karsdal Shareholder of: Nordic Bioscience, Employee of: Nordic Bioscience DOI: 10.1136/annrheumdis-2018-eular.3028

\section{THU0102 HIGH RATES OF RESIDUAL DISEASE ACTIVITY DESPITE CURRENT THERAPIES IN A REAL LIFE RHEUMATOID ARTHRITISCOHORT: DATA FROM 1096 PATIENTS}

K. Thomas ${ }^{1}$, A. Lazarini ${ }^{1}$, E. Kaltsonoudis ${ }^{2}$, A. Drosos ${ }^{2}$, P. Tsatsani ${ }^{3}$, S. Gazi ${ }^{3}$, L. Pantazi ${ }^{4}$, K.A. Boki ${ }^{4}$, P. Katsimbri ${ }^{1}$, D. Boumpas ${ }^{1}$, K. Fragkiadaki ${ }^{1}$, M. Tektonidou ${ }^{1}$, P.P. Sfikakis ${ }^{1}$, K. Karagianni ${ }^{5}$, L. Sakkas ${ }^{5}$, E. Grika ${ }^{1}$, P. Vlachoyiannopoulos ${ }^{1}$, G. Evangelatos ${ }^{6}$, A. lliopoulos ${ }^{6}$, T. Dimitroulas $^{7}$ A. Garyfallos ${ }^{7}$, K. Melissaropoulos ${ }^{8}$, P. Georgiou ${ }^{8}$, M. Areti ${ }^{9}$, C. Georganas ${ }^{10}$ P. Vounotrypidis ${ }^{11}$, G. Kitas ${ }^{1}$, D. Vassilopoulos ${ }^{1}$, on behalf of Greek Rheumatology Society RA Study Group. ${ }^{1}$ Joint Rheumatology Program, National and Kapodistrian University of Athens School of Medicine, Athens; ${ }^{2}$ Rheumatology Clinic, University of loannina, loannina; ${ }^{3}$ Rheumatology Unit, KAT Hospital; ${ }^{4}$ Rheumatology Unit, Sismanoglio Hospital, Athens; ${ }^{5}$ Department of Rheumatology, University of Thessaly, Larissa; ${ }^{6}$ Rheumatology Unit, NIMTS Hospital, Athens; ${ }^{7}$ 4th Department of Medicine, Aristotle University, Thessaloniki; ${ }^{8}$ Rheumatology Unit, Agios Andreas Hospital, Patras; ${ }^{9}$ Private Practice, Livadeia; ${ }^{10}$ Private Practice, Athens; ${ }^{11}$ Private Practice, Thessaloniki, Greece

Background: It is unclear if the widespread use of biologic DMARDs (bDMARDs) and the implementation of the treat to target approach have led to better disease control in patients with rheumatoid arthritis (RA) in daily clinical practice.

Objectives: To study the longitudinal changes in disease activity in a large, real life, longitudinal RA cohort.

Methods: Multicenter (11 hospitals, 3 private offices), prospective, RA epidemiological study in Greece. Demographics, disease characteristics, treatments and co-morbidities were collected via a web-based platform in registered patients at baseline and one year after their 1st visit.

Results: 1.096 RA patients with available paired evaluations one year apart (mean interval: $13.4 \pm 3.6$ months) were included (women: $78 \%$, mean age: 62.8 years, mean disease duration: 11 years, RF and/or anti-CCP positive: 60\%, mean HAQ: $0.44 \pm 0.56)$. At baseline, $50 \%(n=548)$ of patients were on conventional DMARDs (csDMARDs) alone, $35 \%$ on cs- and b-DMARD combination $(n=379)$ and $11 \%$ on bDMARD monotherapy $(n=124)$. Among bDMARD treated patients, $60 \%$ were 
receiving tumour necrosis factor inhibitors (TNFi) while $40 \%$ were on corticosteroids (mean daily dose: $4.7 \mathrm{mg}$ ). Despite these therapies, $43 \%$ of patients had active disease (DAS28-ERS>3.2); 34\% moderate (MDA, DAS28-ESR=3.2-5.1) and $9 \%$ high (HDA, DAS28-ESR $>5.1$ ) disease activity. During the 1 year observation period, among the group of patients with MDA who were only on csDMARDs, $15 \%$ started a bDMARD while among those on bDMARDs, $11 \%$ switched to another bDMARD. The respective rates of starting a bDMARD (in those on csDMARDs) or switching to another bDMARD (in those on bDMARDs), were much higher for patients in the HDA group ( $41 \%$ and $32 \%$ respectively, $p<0.001$ for both groups). At the end of the 1 st year, the proportion of patients on TNFi and corticosteroids was $57 \%$ and $32 \%$, respectively. Overall, despite a decrease in the DAS28-ESR score (from $3.2 \pm 1.2$ to $2.9 \pm 1.3, p<0.001), 37 \%$ of patients had still active disease $(6 \%$ improvement after 1 year; MDA: 30\%, HDA: $7 \%$ ).

Conclusions: In a large, real life, RA cohort with almost half of patients on bDMARD-based therapies, more than one third of patients had still active disease at the end of the 1st year of follow-up. These findings could be explained in part by the low rate of bDMARD initiation or switching in this cohort or they could indicate the limitations of current therapeutic approaches in RA patients with longstanding disease in Greece.

Acknowledgements: Supported by grants from the Greek Rheumatology Society and Professional Association of Rheumatologists.

Disclosure of Interest: None declared

DOI: 10.1136/annrheumdis-2018-eular.6944

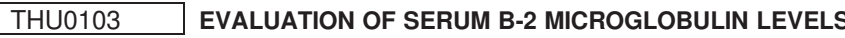 AND ITS RELATIONSHIP WITH DISEASE ACTIVITY IN RHEUMATOID ARTHRITIS}

A.B. Kelesoglu Dincer, M. Torgutalp, E.G. Aydemir Gülöksüz, M.E. yayla, E. Uslu Yurteri, I.E. Okatan, S. Sezer, G. Kinikli, T.M. Turgay, A. Ateș. Rheumatology, Ankara University Faculty of Medicine Rheumatology Department, Ankara, Turkey

Background: $\beta-2$ microglobulin ( $\beta 2 M G$ ) is produced and secreted from $T$ and $B$ lymphocytes. In autoimmune diseases, due to lymphocyte activation and proliferation, serum $\beta 2 M G$ level is expected to be higher than normal. In a few studies, increased serum and synovial fluid $\beta 2 M G$ levels in rheumatoid arthritis (RA) were reported.

Objectives: The aim of this study was to evaluate the concentration of $\beta 2 \mathrm{MG}$ in peripheral blood in RA patients and to show its relationship with disease activity. Methods: In this study, 121 RA patients and 50 sex and age matched healthy controls were enrolled. Patients who had other inflammatory diseases or any kind of malignancy were excluded.

Results: The mean age of RA patients (97 female and 24 male) were 55 years ( \pm 10.9 years) and mean disease duration was 9 years (min: 6 months, max: 42 years). The demographic data of patients and healthy controls are shown in table 1. There was a statistically significant difference between haemoglobin, erythrocyte sedimentation rate and C-reactive protein levels between two groups $(p<0.001$, $p<0.001, p=0.001$ respectively). Serum $\beta 2 M G$ levels were higher in RA group than healthy controls. $(p<0.001)$ When RA patients were grouped according to disease activity as remission to low disease activity(DAS28-ESR<3.2) $(n=65)$ and moderate to severe disease activity(DAS28-ESR $\geq 3.2)(n=56)$, the serum $\beta 2 M G$ levels were higher in DAS28-ESR $\geq 3.2$ group than in DAS28-ESR $<3.2$ group $(p=0.003)$. The difference between serum $\beta 2 M G$ levels were statistically significant in low and high disease activity groups when grouped both according to DAS-ESR and DAS-CRP $(\mathrm{p}=0.003$ and $\mathrm{p}=0.006$, respectively). The seropositivity between two groups were similiar $(p=0.385$ ), although serum ESR, CRP levels and the rate of morning stiffness were significantly higher in high disease activity group. The results were shown in table 2. According to Spearmann correlation test, the serum $32 \mathrm{MG}$ level and DAS-ESR and DAS-CRP were positively correlated which were both statistically significant. $(r=0.378, p<0.001$ and $r=0.324, p<0.001$ respectively).

Abstract THU0103 - Table 1. Baseline characteristics of RA patients and healthy controls

\begin{tabular}{lccc}
\hline Characteristics & $\mathrm{RA}(\mathrm{n}=121)$ & $\begin{array}{c}\text { Control } \\
(\mathrm{n}=50)\end{array}$ & p value \\
\hline $\begin{array}{l}\text { Female Sex, } \\
(\%)\end{array}$ & $97(80.2)$ & $35(70.0)$ & 0.150 \\
Age, years & $55.0 \pm 10.9$ & $52.6 \pm 10.6$ & 0.183 \\
WBC & 7736 & $7170 \pm 1759$ & 0.139 \\
& \pm 3177 & & \\
Hb & $12.6 \pm 1.5$ & $14.1 \pm 1.7$ & $<0.001$ \\
Thrombocyte & 290.4 & $279.7 \pm 65.2$ & 0.441 \\
& \pm 88.9 & & \\
ESR & $24.3 \pm 17.0$ & $12.2 \pm 8.2$ & $\mathbf{0 . 0 0 1}$ \\
CRP (IQR) & $2.5(4.7)$ & $6.1(10.7)$ & $\mathbf{0 . 0 0 1}$ \\
$\beta 2-$ microglobulin & $2.93 \pm 1.20$ & $2.21 \pm 0.54$ & $<\mathbf{0 . 0 0 1}$ \\
DAS28-ESR & $3.30 \pm 1.16$ & & \\
DAS28-CRP & $3.60 \pm 1.39$ & & \\
\hline
\end{tabular}

Abstract THU0103 - Table 2. Baseline characteristics of RA patients

\begin{tabular}{lccc}
\hline & $\begin{array}{c}\text { DAS28-ESR } \leq 3.2 \\
(\mathrm{n}=65)\end{array}$ & $\begin{array}{c}\text { DAS28-ESR>3.2 } \\
(\mathrm{n}=56)\end{array}$ & p value \\
\hline Female Sex, $\mathrm{n}(\%)$ & $48(73.8)$ & $29(87.5)$ & 0.060 \\
Age, years & $53.4 \pm 11.3$ & $56.9 \pm 10.1$ & 0.079 \\
ESR & $17.8 \pm 12.3$ & $31.9 \pm 18.6$ & $<0.001$ \\
CRP (IQR) & $4.0(7.9)$ & $10.2(12.6)$ & $<0.001$ \\
B2-microglobulin & $2.62 \pm 0.87$ & $3.29 \pm 1.42$ & $\mathbf{0 . 0 0 3}$ \\
DAS28-ESR & $2.42 \pm 0.59$ & $4.31 \pm 0.78$ & $<0.001$ \\
DAS28-CRP & $2.67 \pm 0.61$ & $4.67 \pm 2.26$ & $<0.001$ \\
Morning stiffness, $\mathrm{n}(\%)$ & $13(20)$ & $24(42.9)$ & $\mathbf{0 . 0 0 7}$ \\
\hline
\end{tabular}

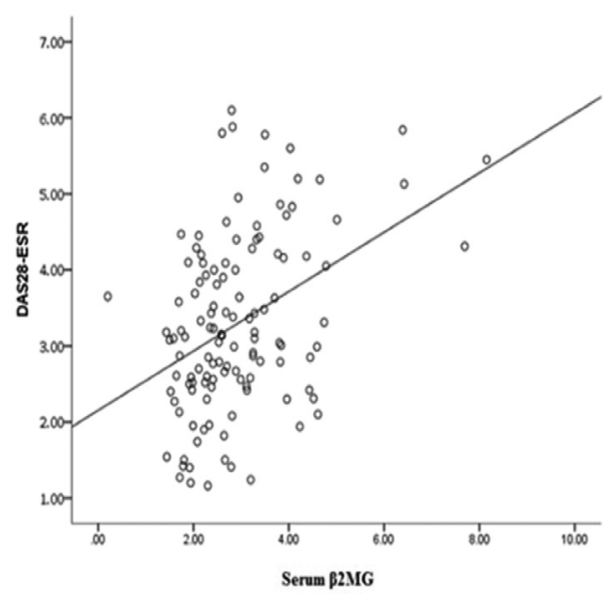

Abstract THU0103 - Figure 1. The figüre that shows the relationship of serum $\beta 2 M G$ with DAS28-ESR

Conclusions: Our results show that serum $\beta 2 M G$ concentration increase in RA and is higher in active patients. It can be concluded that serum $\beta 2 M G$ may be an appropriate parametre to monitor disease activity in rheumatoid arthritis.

Disclosure of Interest: None declared

DOI: 10.1136/annrheumdis-2018-eular.4258

\section{THU0104 THE TEMPORAL PROFILE OF ANTIBODIES DIRECTED AGAINST POST-TRANSLATIONAL MODIFICATIONS VARIES ACCORDING TO ISOTYPE AND TARGET IN PATIENTS WITH NEW-ONSET RHEUMATOID ARTHRITIS}

B. Dyke $^{1}$, M. Juarez ${ }^{2}$, H. Bang ${ }^{3}$, C.D. Buckley ${ }^{1}$, A. Filer ${ }^{1}$, K. Raza ${ }^{1}{ }^{1}$ University of Birmingham, Birmingham; ${ }^{2}$ UCB Pharma, Slough, UK; ${ }^{3}$ Orgentec Diagnostika GmBH, Mainz, Germany

Background: Autoantibodies directed against antigens with post-translational modifications (PTMs), such as citrullination (ACPA), are a hallmark of rheumatoid arthritis (RA) ${ }^{1}$. ACPA titres increase prior to disease onset, but are thought to be relatively stable after symptomatic inflammation is established ${ }^{2}$. The temporal profile of antibodies against acetylated (AAPA) and carbamylated (ACarPA) peptides has not been so comprehensively characterised following the onset of joint swelling ${ }^{3}$

Objectives: We aimed to track serum levels of anti-PTM antibodies over 18 months in patients with newly-presenting RA in our prospective observationa cohort.

Methods: Patients with treatment-naïve inflammatory arthritis donated serum at baseline, 6 and 18 months. 103 patients satisfying ACR/ ${ }^{\text {EULAR } 2010}$ criteria for RA underwent testing for $\lg G$ and $\lg A$ antibodies against peptides with citrulline (ACPA), carbamylated lysine (ACarPA), and acetylated lysine (AAPA) PTMs using ELISA as previously described ${ }^{4}$.

Results: $57 \%$ of participants were female, and $48 \%$ and $50 \%$ patients were antiCCP2 or rheumatoid factor positive respectively. Mean age was 56 years (s.d. 15.2), symptom duration 55 days (s.d 22.4), and DAS28CRP 4.4 (s.d. 1.3) at enrolment.

Comparing baseline and 18 month median antibody levels measured by optical density, a decrease was observed over time for $\lg \mathrm{G}(0.26$ vs $0.17, \mathrm{p}<0.0001)$ and $\lg$ A APA (0.23 vs $0.09, p<0.0001)$, as well as both $\lg G$ and $\lg A$ antibodies against citrullinated peptides ( 0.47 vs $0.40, p<0.0001$ and 0.16 vs $0.12, p<0.0001$ respectively). Significant reductions occurred between baseline and 6 months for both $\lg G(p<0.0001)$ and $\lg A(p<0.0001)$ AAPA antibodies, but not between 6 and 